\title{
Influence of Pyrolysis Temperature on Product Distribution and Characteristics of Anaerobic Sludge
}

\author{
Muhammad Usman Hanif ${ }^{1}$, Mohammed Zwawi ${ }^{2}$, Sergio C. Capareda ${ }^{3}$, Hamid Iqbal ${ }^{4}$, \\ Mohammed Algarni ${ }^{2}$, Bassem F. Felemban ${ }^{5}$, Ali Bahadar 6,*(D) and Adeel Waqas ${ }^{7}$ (D) \\ 1 Institute of Environmental Science and Engineering, School of Civil and Environmental Engineering, \\ National University of Sciences and Technology, Sector H-12, Islamabad 44000, Pakistan; \\ usman_hanif90@live.com \\ 2 Department of Mechanical Engineering, King Abdul Aziz University, Rabigh 21911, Saudi Arabia; \\ mzwawi@kau.edu.sa (M.Z.); malgarni1@kau.edu.sa (M.A.) \\ 3 Bio-Energy Testing and Analysis Laboratory (BETA Lab), Biological and Agricultural Engineering \\ Department, Texas A\&M University, College Station, TX 77843, USA; scapareda@tamu.edu \\ 4 Rawalpindi Waste Management Company, A-81, Iran Road, Satellite Town, Rawalpindi 46000, Pakistan; \\ hamid_nust@yahoo.com \\ 5 Mechanical Engineering Department, Taif University, Taif 21974, Saudia Arabia; b.felemban@tu.edu.sa \\ 6 Department of Chemical and Materials Engineering, King Abdul Aziz University, Rabigh 21911, \\ Saudi Arabia \\ 7 Center for Advanced Studies in Energy, National University of Sciences and Technology, Islamabad 44000, \\ Pakistan; adeelwaqas@gmail.com \\ * Correspondence: absali@kau.edu.sa
}

Received: 25 November 2019; Accepted: 18 December 2019; Published: 23 December 2019

\begin{abstract}
Pyrolysis of anaerobically digested sludge can serve as an efficient biomass for biofuel production. Pyrolysis produces products like char, bio-oil, and combustible gases by thermochemical conversion process. It can be used for sludge treatment that decreases sludge disposal problems. Sludge produced from anaerobic co-digestion (microalgae, cow dung, and paper) waste has high carbon and hydrogen content. We investigated the candidacy of the anaerobic sludge having high heating value (HHV) of $20.53 \mathrm{MJ} / \mathrm{kg}$ as a reliable biomass for biofuels production. The process of pyrolysis was optimized with different temperatures $\left(400,500\right.$, and $\left.600^{\circ} \mathrm{C}\right)$ to produce high quantity and improved quality of the products, mainly bio-oil, char, and gas. The results revealed that with the increase in pyrolysis temperature the quantity of char decreased ( $81 \%$ to $55 \%)$, bio-oil increased ( $3 \%$ to $7 \%$ ), and gas increased ( $2 \%$ to $5 \%$ ). The HHV of char $(19.2 \mathrm{MJ} / \mathrm{kg})$, bio-oil $(28.1 \mathrm{MJ} / \mathrm{kg})$, and gas $(18.1 \mathrm{MJ} / \mathrm{kg})$ were predominantly affected by the amount of fixed carbon, hydrocarbons, and volatile substance, respectively. The study confirmed that the anaerobic sludge is a promising biomass for biofuel production and pyrolysis is an efficient method for its safe disposal.
\end{abstract}

Keywords: anaerobic sludge; pyrolysis; hydrocarbon; alternate energy; bio-oil

\section{Introduction}

Global increase in population, urbanization, and industrialization has not only increased pressure on natural resources but also resulted in generation of a higher quantity of waste and sludge than ever. Sludge management is critical, as sludge disposal needs to be done in accordance with strict environmental regulations. Safe sludge disposal has become an important concern in urban areas [1]. The sludge treatment and disposal usually involves incineration, landfilling, and composting techniques. Sludge is a heterogeneous mixture of both organic and inorganic matter, whose composition is further defined by feedstock, digestion method, reaction time, and reaction conditions [2]. In addition, 
anaerobic sludge produced by the waste stabilization process is rich in microbes, extra-cellular polymeric substances, and recalcitrant material [3]. The sludge may also contain few inorganic species like calcium, phosphorus, and metals [4], although the quantity of these species is completely dependent on the feedstock.

Different biomass is being focused these days as a feedstock for hydrocarbon production as alternate energy. The properties that make biomass a better hydrocarbon producing feedstock includes high yielding capacity, low energy input requirements, low cost of conversion, minimum contaminants, and low additional nutrient requirements. These requirements are mostly satisfied in agriculture products, animal dung/manure, and municipal wastes [5,6]. High cellulose, hemicellulose, and lignin content in feedstock are the key players for having better quantity and quality of hydrocarbons or biofuels. The conversion of biomass to bio-fuel requires an efficient process that can increase the heating values per unit weight of material (both biomass and biofuel).

Riley and Forster [7] reported high heating values of raw sludge owing to ultimate properties that were almost similar to that of wood [8]. The stabilized sludge comparatively has a low heating value as $\mathrm{CO}_{2}$ and $\mathrm{C}_{n} \mathrm{H}_{n}$ is lost during the stabilization process [9]. The sludge produced by anaerobic digestion of waste and sludge (as inoculum) comparatively has higher quantity of carbon, hydrogen, and oxygen than the stabilized sludge. The anaerobic sludge has higher heating value making it a better feedstock for thermal conversion into bio-fuels.

Among the common methods for bio-fuel production (gasification, liquefaction, and pyrolysis), pyrolysis has gained much attention in the science community because of its efficiency of recycling wastes into valuable products $[10,11]$. Gasification consists of converting liquid or solid organic biomass in to gaseous or vapor phase and in to solid final products. Solid products include tar, char, and ash contents. While gaseous form is termed as syngas. Syngas can be used to run power generating units or for production of bio-fuels. Solid state final product is usually called char which is mixture of unconverted biomass fractions and different materials of initial bio-mass. Different carrier gases such as $\mathrm{CO}_{2}$, steam, and $\mathrm{O}_{2}$ facilitate conversion reactions. Huge amount of energy can be produced and bio-mass can be effectively used through gasification process [12]. Molino et al. used a pilot-scale rotary kiln for refuse-derived fuel (RDF) steam gasification testing. Evaluation of gas features was done at fixed temperature $\left(850^{\circ} \mathrm{C}\right.$ ) and changing feed ratio (FR) in between 0.4 to 2.67 . Before analyzing the end results in case of FR increment in energy content and composition, many experiments were performed for key operating variables such as gas and solid residue time, kiln temperature, etc., to get the best and correct values. Energy content of gas decreased with the increase in FR. Maximum value for energy content was obtained at $\mathrm{FR}=0.4$, having a volumetric gas composition of $\mathrm{H}_{2}(59.1 \% \mathrm{v} / \mathrm{v})$, $\mathrm{CO}(20.1 \% \mathrm{v} / \mathrm{v}), \mathrm{CH}_{4}(3 \% \mathrm{v} / \mathrm{v})$ with the peak value of $16 \mathrm{MJ} / \mathrm{kg}_{\text {gas }}$ for lower heating value (LHV) [13]. Chianese et al. investigated water gas shift (WGS) reaction for production of hydrogen to study the activity of commercially available catalyst cobalt/molybdenum (Co/Mo). The experiment was carried out in a three-fixed-bed reactor pilot plant with tar-enriched gas as feed stream from full scale biomass gasification plant. To evaluate selectivity of water gas shift reaction and $\mathrm{CO}$ conversion (XCO) for operating temperature $\left(300-450{ }^{\circ} \mathrm{C}\right)$, a parametric variational analysis was performed and (XCO) was found close to $85 \%$ [14]. The capability of WGS catalyst system for portable application goes through required decrements in reactor volume, which is usually obtained by utilizing less charge of high efficiency catalyst. Nuria et al. projected a completely new idea for catalyst designing. The new proposed catalytic system included WGS catalysts such as $\mathrm{Cu}$, Pt or Au with mechanical mixing of ionic conductor. It is indispensable to have contact between WGS catalyst and ionic conductor for uninterrupted water supply leading to the importance of the water activation step independent of catalytic performance and mechanism. Multi-component catalytic systems based on mixture of WGS catalyst and ionic conductor have added advantages in catalytic activity [15]. In another research study, the catalyst gasification was carried out using thermogravimetric analyzer with mass spectrometry on two lipid-extracted microalgae biomass, Chlorella vulgaris and Spirulina platensis. Effects of catalytic loading (10-50 wt.\%) was studied using CaO-based catalyst derived from eggshells. Reactions were 
carried out in temperature range of 30 to $800{ }^{\circ} \mathrm{C}$ with $5 \% \mathrm{O}_{2} / \mathrm{Ar}$ and at flow rate of $500 \mathrm{~mL} / \mathrm{min}$. In case of Spirulina platensis, hydrogen showed significant increase in yield from $53.6 \%$ to $110 \%$, while $\mathrm{CO}_{2}$ and $\mathrm{CO}$ showed decrement in yields by $52 \%$ and $58 \%$, respectively. In case of Chlorella vulgaris, hydrogen yield was enhanced by the increment in catalytic loading from $21.2 \%$ to $114.4 \%$. On the other hand, $\mathrm{CO}_{2}$ and $\mathrm{CO}$ yield decreased by $55 \%$ and $50 \%$, respectively, when compared to without catalyst. Hydrogen production was increased with the increase in catalytic activity of $\mathrm{CaO}$ and capturing of $\mathrm{CO}_{2}$, which enhanced the water-gas shift reaction [16].

Pyrolysis involves thermo-chemical valorization of biomass into energy and has high feed-to-fuel ratio with multiple optimization options that favor product yields (biochar, bio-oil, or gas production) [17]. The optimization controls generally include reactor design, process parameters, biomass type, and its characteristics. These controls affect both quantity and quality of product yields [18]. Temperature governs the chemical processes of dehydration, dehydrogenation, depolymerization, fragmentation, and thermal cracking of facultative products during pyrolysis [6]. Optimizing pyrolysis through temperature is a key to maximize the product yields [19]. A thorough analysis of biomass conversion at different temperatures could be used to select the suitable temperature for desired quantity and quality of products.

In this study, sludge produced from anaerobic co-digestion is pyrolyzed to produce valuable products as a waste to resource (W2R) option. The anaerobic co-digestion helps in recovering energy from the feedstock and further pyrolysis of the sludge can recover the fixed energy in the form sludge, which is usually wasted in the landfills. Therefore, the study uses two high-tech processes of energy recovery (i.e., digestion and pyrolysis), in-line to recover maximum energy from the biomass. Further, it was hypothesized that by changing temperature, a wide range of products can be produced by pyrolyzing anaerobic sludge.

\section{Materials and Methods}

\subsection{Characterization of Anaerobic Sludge}

Sludge was obtained after 92 days of anaerobic co-digestion of microalgae, cow dung, anaerobic sludge (as inoculum), and shredded paper (used to balance the C:N ratio). The sludge was homogenized by mixing and dried in an oven at $105^{\circ} \mathrm{C}$ for the time when moisture content reached $0.1 \mathrm{~kg}$ of $\mathrm{H}_{2} \mathrm{O} / \mathrm{kg}$ of dried mass. The dried sludge was ground in a Wiley Laboratory Mill (Model No. 4, Arthur Thomas Company, PA) to obtain an average particle size of $2 \mathrm{~mm}$. Higher heating value (HHV) was determined following standard method (ASTM, D2015) using PARR isoperibol bomb calorimeter (Model 6200, Parr Instrument Company, Moline, IL, USA). Meanwhile, moisture content was confirmed again and proximate analysis was done according to standard method (ASTM D3175 and E1755). A Vario MICRO Elemental Analyzer (Elementar Analysemsysteme GmbH, Germany) was used for the ultimate analysis of sludge using standard method (ASTM D3176).

\subsection{Pyrolysis}

Pyrolysis experiment was conducted using a fixed-bed batch-type pyrolysis reactor (Series 4580 HP/HT, Parr Instrument Company, Moline, IL, USA) using $180 \mathrm{~g}$ of sludge for each run. Prior to pyrolysis, oxygen was purged out of the system by introducing nitrogen. Throughout the process, the media was constantly mixed at $550 \mathrm{rpm}$ using a stirrer attached to a magnetic drive. Starting from room temperature, the reactor temperature increased at a rate of $5.5^{\circ} \mathrm{C} /$ minute until the desired temperature was attained and the reaction was allowed to continue for $30 \mathrm{~min}$. Reactor temperatures of 400,500 , and $600{ }^{\circ} \mathrm{C}$ were used for iterations. All experimental runs were carried out in triplicate. The experimental setup used for the study is already reported in detail by [17]. 


\subsection{Product Yields}

Volume of gas was measured by a gas meter (METRIS 250, Iron, Owenton, KY, USA) while the amounts of liquid and char were measured using an analytical balance. Char, bio-oil, and gas yields were calculated on mass basis using the following equation:

$$
P(w t)=\frac{P_{m}}{S_{m}}
$$

Where $P$ is product yield, $P_{m}$ is mass of product, and $S_{m}$ is the mass of dry anaerobic sludge feed. A mass balance within the reactor was set up using mass conversion rates and losses during conversion (Equation (2)). Total energy loss and energy yield was determined by Equation (3) and used into Equation (2).

$$
Y_{b}+Y_{g}+Y_{c}+L=1 \text { or }[\times 100] \%
$$

where $Y_{b}$ is bio-oil yield, $Y_{g}$ is gas yield, $Y_{c}$ is char yield, and $L$ are the losses.

$$
Y_{e}=P(w t) \frac{H V_{\text {Product }}}{H V_{\text {anaerobicsludge }}}
$$

where $Y_{e}$ energy yield and HV is the heating value of the subscripts. Statistical analysis of the data was done for the analysis of variance (ANOVA) at $95 \%$ confidence level was performed on the resulted data for statistical significance.

\subsection{Chemical Analysis}

The HHVs of char and bio-oil were measured and the proximate and ultimate analyses of the materials were done using the standard methods described above. Determination of density, ash, and moisture content of the bio-oil was performed using standard methods ASTM D1217-93, D0482-07 and E203, respectively. Furthermore, the chemical composition of bio-oil was determined by GC-MS (Shimadzu QP2010 Plus, Germany) using dichloromethane (10\% vol) as solvent and a DB-5 MS column. Functional groups were determined using a Fourier transform infrared (FT-IR) spectrophotometer (Shimadzu, IR Affinity-1 with a MIRacle universal sampling accessory) within 700 to $4000 \mathrm{~cm}^{-1}$ range, at a resolution of $4 \mathrm{~cm}^{-1}$. Gas samples were obtained in 1-L Tedlar sampling bags provided with combination valve and fed into a multiple gas analyzer (MG\#1) gas chromatograph (SRI, USA) with on-column injection system to determine composition. Helium ionization detector (HID) and thermal conductivity detector (TCD) were interfaced with the gas chromatography for detection of separated gas species. Initial temperature of the column was set at $65^{\circ} \mathrm{C}$ for $10 \mathrm{~min}$ then decreased at $16^{\circ} \mathrm{C} / \mathrm{min}$ to the maximum temperature of $250{ }^{\circ} \mathrm{C}$.

\section{Results and Discussion}

\subsection{Characteristics of Anaerobic Sludge}

The characteristics of anaerobic sludge are compared with stabilized sludge, raw sludge, and wood in Table 1. Data show that the dried anaerobic sludge had a bulk density of $412 \mathrm{~kg} / \mathrm{m}^{3}$, indicating a dense biomass. This property should lead to lower transport and storage cost, especially on a large scale. On the other hand, the HHV of anaerobic sludge is same as wood, highlighting its applicability as an efficient biomass for energy production. Further comparison of the HHV of the other sludges shows that raw sludge has a higher value, while the stabilized sludge has a lower value, demonstrating that $\mathrm{HHV}$ is a function of the nature and type of feedstock used in the anaerobic digestion. The anaerobic sludge contains $63 \%$ volatile combustible matter, which is the major component in the feedstock conversion into products. The amount of char produced is in turn determined by the amounts of fixed-carbon and ash. For the aerobic sludge, the total amounts of fixed-carbon and ash remained at 
released. For the anaerobic sludge, the total amount of fixed-carbon and ash contents remained at $23 \%$ and $14 \%$, respectively.

Table 1. Characteristics of feedstocks in comparison with wood as a perfect material for pyrolysis.

\begin{tabular}{cccccc}
\hline \multicolumn{2}{c}{ Biomass Characteristics } & $\begin{array}{c}\text { Anaerobic } \\
\text { Sludge }\end{array}$ & $\begin{array}{c}\text { Stabilized } \\
\text { Sludge }\end{array}$ & Raw Sludge $^{\infty}$ & Wood $^{*}$ \\
\hline Bulk density $\left(\mathrm{kg} / \mathrm{m}^{3}\right)$ & & 412 & - & - & - \\
HHV (MJ/kg) & VCM & 20.53 & $16.6^{\dagger}$ & 23.45 & $20.5^{\bullet}$ \\
Proximate analysis & Fixed Carbon & 22.85 & $55.48^{\ddagger}$ & - & $79.72^{+}$ \\
& Ash & 14.4 & $12.46^{\ddagger}$ & - & $19.92^{+}$ \\
& $\mathrm{C}$ & 38.50 & $23.9^{\ddagger}$ & & $0.36^{+}$ \\
Ultimate analysis & $\mathrm{H}$ & 5.084 & $3.55^{\dagger}$ & 52.7 & $53.1^{\bullet}$ \\
& $\mathrm{N}$ & 1.332 & $4.18^{\dagger}$ & 8.39 & $6.4^{\bullet}$ \\
& $\mathrm{S}$ & 1.199 & $1.15^{\dagger}$ & 3.38 & $0.4^{\bullet}$ \\
& $\mathrm{O}$ & 39.49 & $27.24^{\dagger}$ & - & - \\
\hline
\end{tabular}

${ }^{*}$ Experimental values; ${ }^{\dagger}[7] ;{ }^{\ddagger}[9] ;{ }^{\infty}[20] ; \cdot[8] ;^{+}[21]$

Ultimate analysis of the sludge shows high concentrations of combustible components, with $38.5 \%$ carbon content and 5\% hydrogen content. This is expected as the sludge was obtained from animal manure, algae, and paper waste. The carbon and hydrogen contents of the anaerobic sludge are higher than those of the stabilized sludge but lower than those for raw sludge and wood. Lastly, the anaerobic sludge has a lower percentage of nitrogen (1.33\%) compared to the stabilized and raw sludge.

\subsection{Product Yield and Mass Conversion Efficiency}

Data show that product yield and mass conversion efficiency are dependent upon the pyrolysis temperature. Figure 1 shows that the temperature increase also increased the amount of losses. The pie charts show that losses remained the same with temperature rise from 400 to $500{ }^{\circ} \mathrm{C}$. The amount of mass converted by the pyrolysis remained $85 \%$. The increase in reaction time may further decrease the losses at higher temperatures. The proportion of each component of products changed with changing temperatures. The change in product yield is visible from 400 to $500{ }^{\circ} \mathrm{C}$. Char remained the dominant fraction of product yields with aqueous phase as a second most abundant proportion. At $400{ }^{\circ} \mathrm{C}$, char was almost $80 \%$ of the products. Bio-oil and gas collectively accounted for almost $4 \%$ of products. Increasing the temperature further to $600{ }^{\circ} \mathrm{C}$ did not result in significant changes of product yields, indicating that decomposition was mostly completed at $500{ }^{\circ} \mathrm{C}$ [22]. There was a significant decrease $(p$-value $=0.0012)$ in the char yield when the temperature was $\mathrm{r}$ from $400{ }^{\circ} \mathrm{C}$ (char $\left.=67.53 \%\right)$ to $600{ }^{\circ} \mathrm{C}$ (char $=44.14 \%$ ). For bio-oil, increasing the temperature resulted in greater product yield, from $14.38 \%$ at $400{ }^{\circ} \mathrm{C}$ to $33.88 \%$ at $500{ }^{\circ} \mathrm{C}$. At the same temperature range, gas increased from $3.15 \%$ to $5.53 \%$. The histograms in Figure 1 shows the average values of product yields from all runs. 

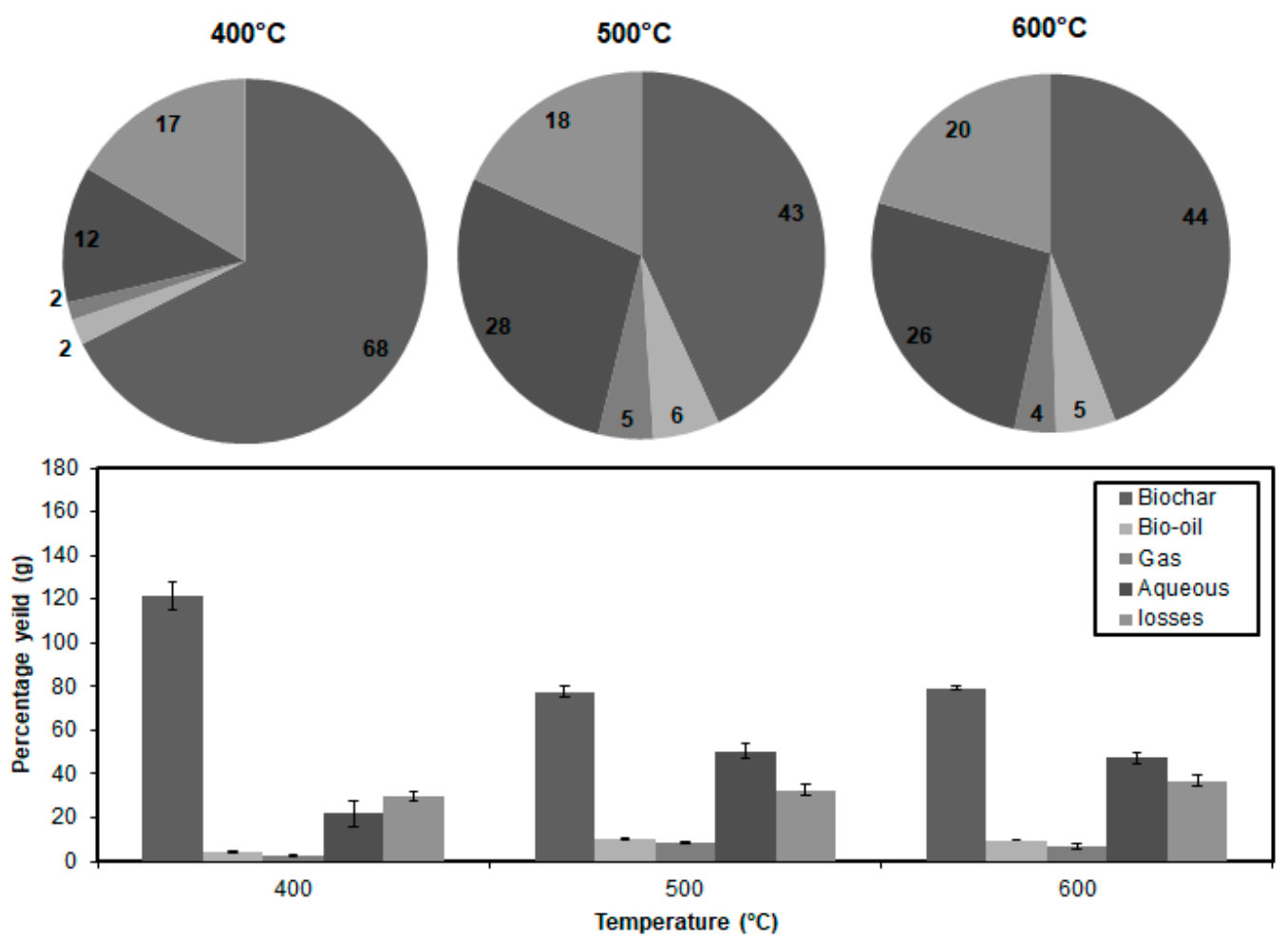

Figure 1. Product yields at different temperatures. The pie charts show percentages of all the products including experimental losses. The histograms show average percentage of product yields with standard deviation as error bars.

\subsection{Quality of Products}

\subsubsection{Char}

The ultimate and proximate analyses of char (Figure 2a,b, respectively) show that chemical composition was generally not affected by temperature. Nevertheless, the proximate analysis shows that there was a significant shift in the proportion of the components of char when the pyrolysis temperatures were changed. As shown in Figure 2b, the proportion of volatile components decreased while the amount of fixed carbon increased during the increment of pyrolysis temperature (400 to $600^{\circ} \mathrm{C}$ ). The amount of ash practically remained unchanged, as can be seen in Figure 2a. The lower ratios of $\mathrm{H}: \mathrm{C}$ and $\mathrm{O}: \mathrm{C}$ show high energy content of biomass, which is explained by the Van Krevelen diagram (Figure 3). The diagram shows these ratios of bio-oil and biochar with other materials. This helps to evaluate the potential application of both the products. Coal has the lowest hydrogen to carbon and oxygen to carbon ratio. The anaerobic sludge and stabilized sludge remained close to soft wood, showing that the amount of oxygen was almost equal to carbon but hydrogen remained almost ten times less than carbon. The raw material (anaerobic sludge) released oxygen to transform into bio-oil and lost water to produce char. Lower temperature produced carbon rich char as compared to higher temperatures. The char can be used for industrial as well as agricultural applications, which may help in reduction of climatic change. 

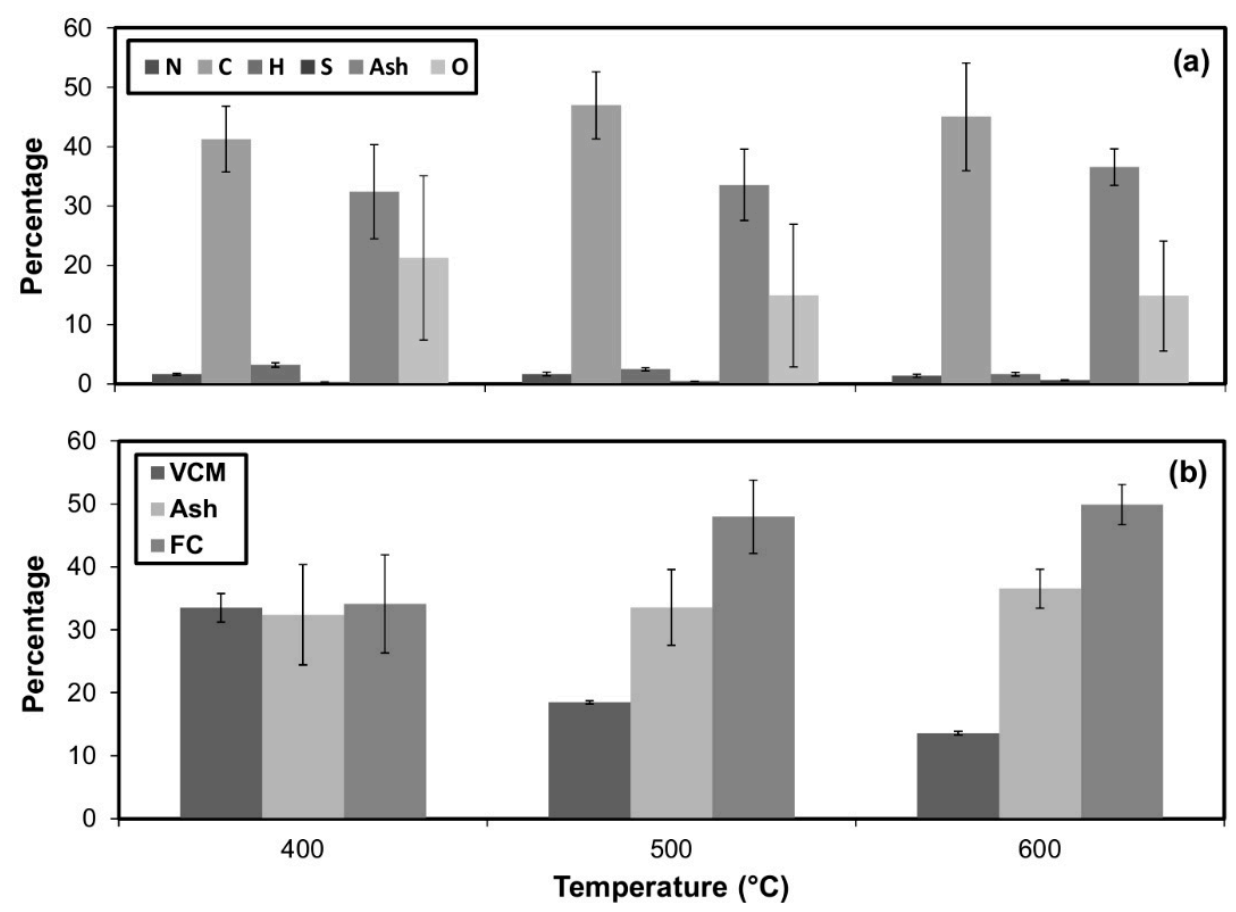

Figure 2. Ultimate (a) and proximate analysis (b) of biochar. The ultimate analysis includes nitrogen, carbon, hydrogen, ash, and oxygen. The proximate analysis involves volatile combustible material, ash, and fixed carbon. The error bars are standard deviation.

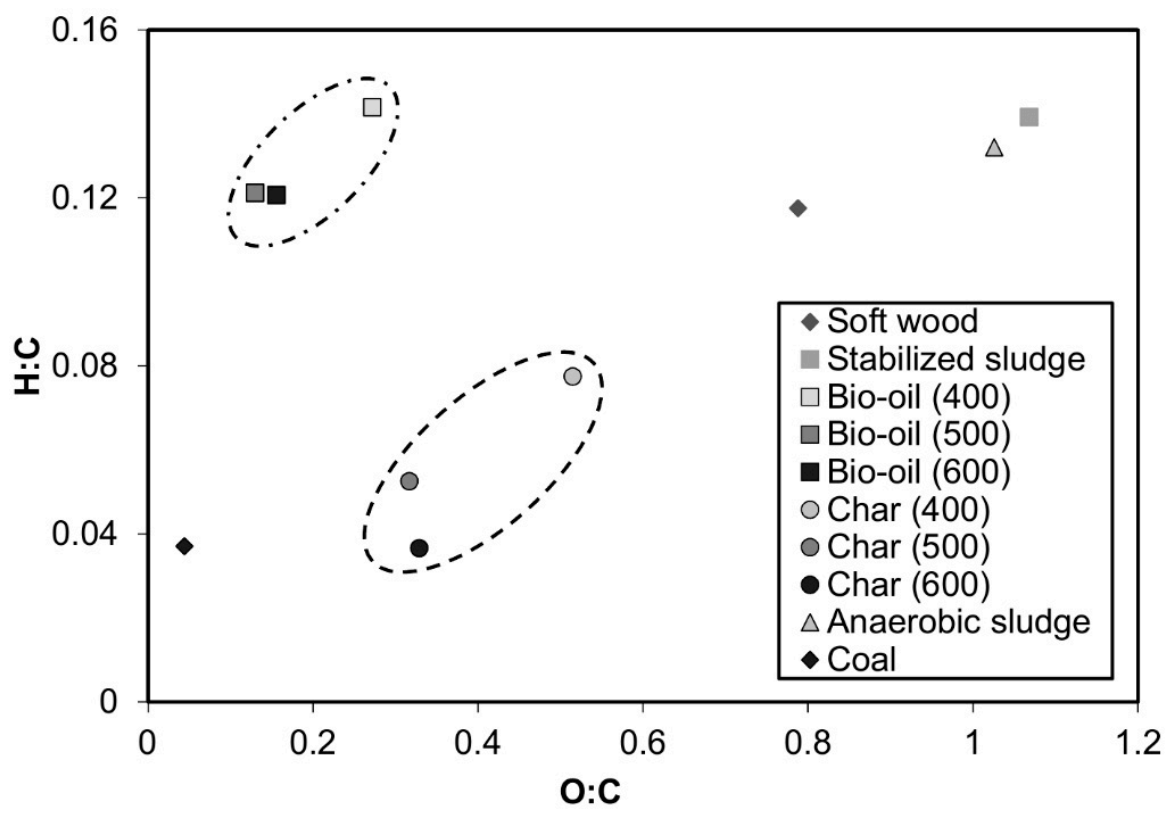

Figure 3. Van Krevelen diagram for bio-oil and char potential applications. The broken circles contain our results.

\subsubsection{Bio-Oil}

The pyrolysis liquid product constitutes two immiscible fractions-(1) a viscous organic and (2) aqueous fractions. The aqueous fraction was yellowish, while the organic fraction was black and resembled the crude oil used in petroleum refineries. Results of characterization assays at different temperatures showed no major change in the elemental composition of bio-oil, indicating that pyrolysis temperature only affected the quantity of bio-oil but not its over-all makeup (Figure 4a). Probably the composition of bio-oil depended on the elemental composition of biomass. On average, bio-oil 
contained carbon, hydrogen, nitrogen, oxygen, sulfur, and ash that remained at 75.08\%, 9.09\%, 4.45\%, $9.73 \%, 1.55 \%$, and $0.08 \%$, respectively. The bio-oil contained lower oxygen content than the sludge but doubled the relative percentage of carbon, nitrogen, and hydrogen. This shows that oxygen was released with gas, leaving behind the carbon and hydrogen. The bio-oil produced is expected to be more stable as the O:C ratio remained low, which denotes an increase in stability.
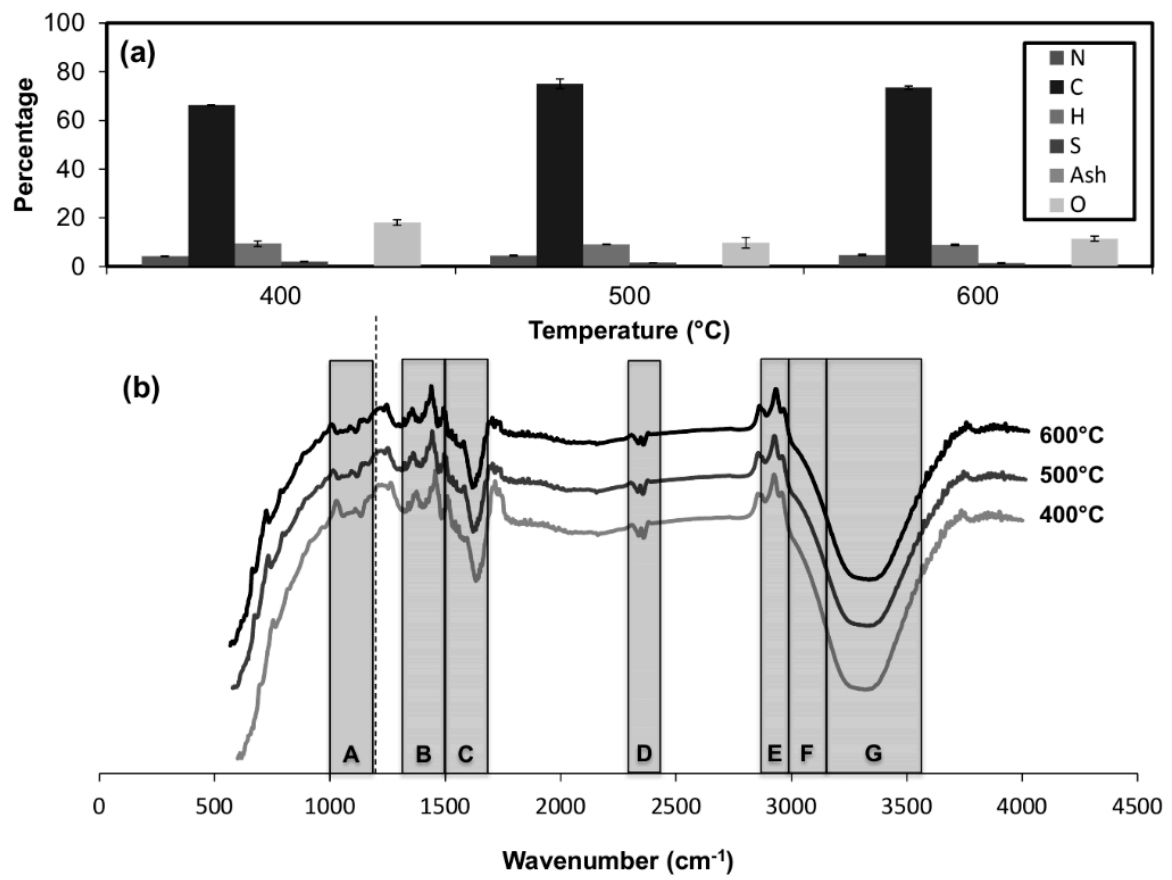

Figure 4. Ultimate analysis (a) and FTIR spectra (b) of bio-oil produced at 400, 500, and $600{ }^{\circ} \mathrm{C}$. The spectral ranges of various compounds are highlighted. Silicates and polysaccharides (A), $\mathrm{CH}_{2}$ and $\mathrm{CH}_{3}$ compounds (B), fatty acids, aldehydes, amides, alkenes, and aromatics (C), C-N groups (D), aliphatics (E), aromatics (F), and water, alcohols, phenols, and carboxylic acids (G).

Bio-oil had a higher hydrogen to carbon ratio and low oxygen to carbon ratio, showing that the content of poly-cyclic aromatics and oxygen-containing aromatic groups are high (Figure $4 \mathrm{~b}$ ). The bio-oils produced at high temperatures are more carbonaceous than bio-oil produced at $400{ }^{\circ} \mathrm{C}$. The sludge has higher concentrations of metals and few of the metals have tendency to catalyze the pyrolysis and oxidation process [22]. This may result in quick conversion of biomass to gaseous phase. On the other hand, metals like calcium do not act as a catalyst but rather shows redundancy in the conversion process [23]. Figure $4 \mathrm{~b}$ shows the FTIR spectra of bio-oil produced at three temperatures.

The overall makeup of bio-oil was not significantly different. The relative concentration of $\mathrm{CH}_{2}$ and $\mathrm{CH}_{3}$ compounds were higher at $400{ }^{\circ} \mathrm{C}$ than bio-oil at high temperatures. At $400{ }^{\circ} \mathrm{C}$, the height of peaks and depth of valley in section $B$ and $C$ were higher than bio-oil produced at 500 and $600{ }^{\circ} \mathrm{C}$, respectively. The relative concentration of $\mathrm{C}-\mathrm{N}$ groups increased with decreasing temperature. There was a negligible change in aliphatics at different temperatures, but the aromatics decreased with decreasing temperatures. Water, phenols, alcohols, and carboxylic acids decreased with decreasing temperature.

The chemical composition (GC-MS) of bio-oil obtained at $500^{\circ} \mathrm{C}$ is shown in Figure 5. The identified compounds were grouped into seven categories; phenols, alkenes, alkanes, benzene, alcohols, ketones, and unknown. The relative abundance of categories of organic species in decreasing order was phenols $>$ alkenes $>$ alkanes $>$ benzene $>$ alcohols $>$ ketones. The highest amount of phenols is a characteristic property of bio-oil produced by biomass, which is minimum in microalgae [17]. These phenols are relatively inexpensive compared to traditional petroleum-based phenols, but at the same time it is not desirable in transportation fuels [24]. The gasoline-like compounds that ensure the better quality of 
bio-oil were found to be $30 \%$. These compounds included alkanes $(12.9 \%)$, alkenes $(9 \%)$, and aromatics $(8.3 \%)$. Alcohols and ketones made up a volume of $4.6 \%$ and $4.3 \%$, respectively.

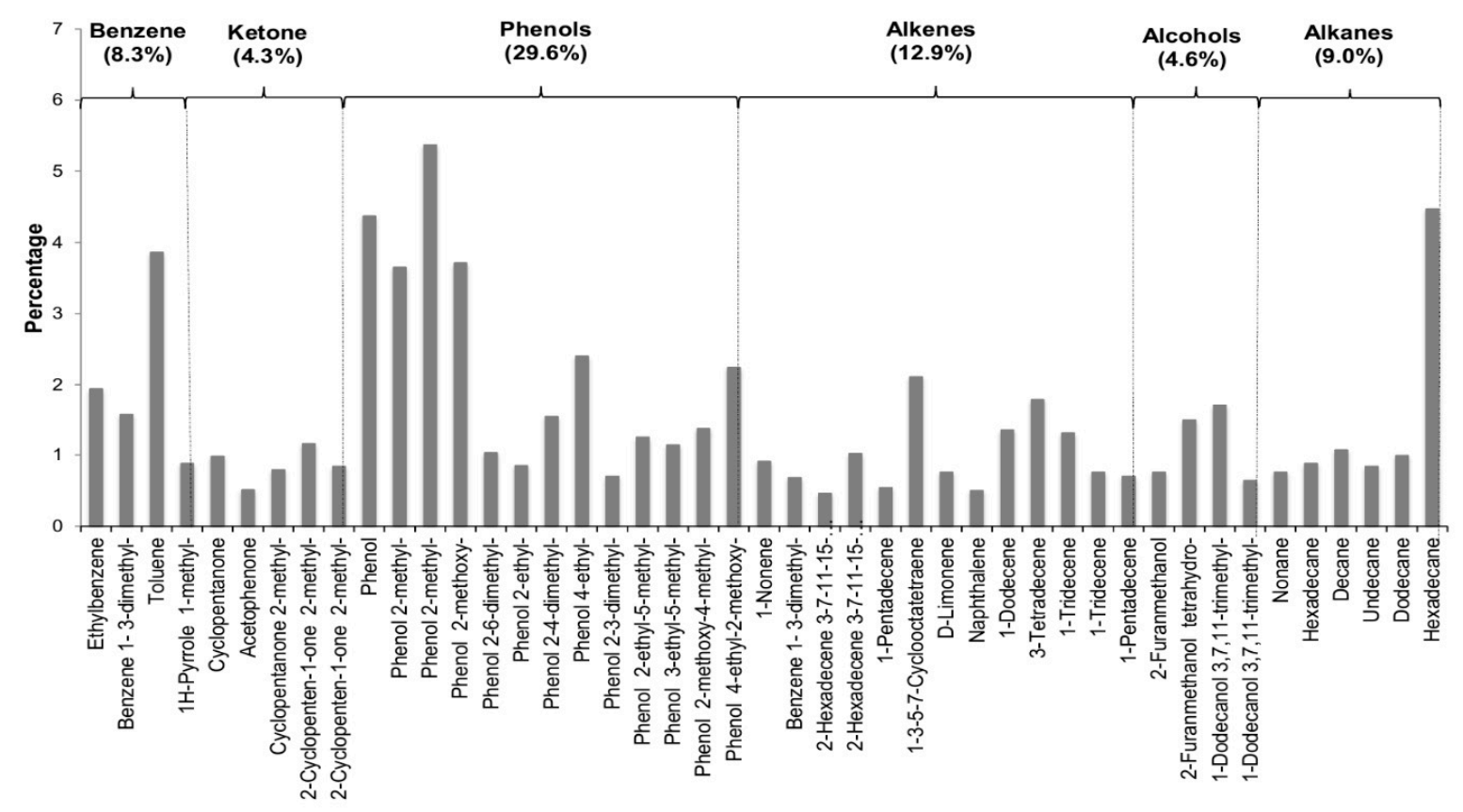

Figure 5. Chemical composition of bio-oil obtained at $500{ }^{\circ} \mathrm{C}$ separated with gas chromatograph and analyzed with mass spectroscopy (GC-MS). Major groups are separated with broken lines in the plot. Note that the percentage of unknown compounds was $31 \%$.

\subsubsection{Gas}

Table 2 presents the profile of gaseous products obtained at different operating temperatures during pyrolysis runs. These gaseous products can be classified into combustible and non-combustible components. The combustible components include $\mathrm{H}_{2}, \mathrm{CO}, \mathrm{CH}_{4}, \mathrm{C}_{2} \mathrm{H}_{4}, \mathrm{C}_{2} \mathrm{H}_{6}, \mathrm{C}_{3} \mathrm{H}_{6}$, and $\mathrm{C}_{3} \mathrm{H}_{8}$. The gaseous profile shows that with increase in temperature the proportion of combustible gases increases. This resulted in a consistent increase of high heating value with temperature. Another study [25] reported that methane has a major share in heating value of gas, as the concentration of methane is higher than other combustible gases. The proportion of non-combustible gases $\left(\mathrm{O}_{2}, \mathrm{~N}_{2}\right.$, and $\mathrm{CO}_{2}$ ) decreased with increasing temperature. At high temperature, $\mathrm{CO}_{2}$ was reduced, which further helped increase in high heating value. The heating values of gas is better than gas produced by glycerol [26,27], but still could not reach the heating value of natural gas $\left(54 \mathrm{MJ} / \mathrm{m}^{3}\right)$.

Table 2. Composition and high heating values of gas at different temperatures.

\begin{tabular}{cccccccccccc}
\hline $\begin{array}{c}\text { Temperature } \\
\left({ }^{\circ} \mathbf{C}\right)\end{array}$ & \multicolumn{1}{c}{ Composition (\% Vol) } & \multicolumn{1}{c}{$\begin{array}{c}\text { Heating Value } \\
\left(\mathbf{M J} / \mathbf{m}^{\mathbf{3}}\right)\end{array}$} \\
\cline { 2 - 13 } & $\mathbf{H}_{\mathbf{2}}$ & $\mathbf{C O}$ & $\mathbf{C H}_{\mathbf{4}}$ & $\mathbf{C}_{\mathbf{2}} \mathbf{H}_{\mathbf{4}}$ & $\mathbf{C}_{\mathbf{2}} \mathbf{H}_{\mathbf{6}}$ & $\mathbf{C}_{\mathbf{3}} \mathbf{H}_{\mathbf{6}}$ & $\mathbf{C}_{\mathbf{3}} \mathbf{H}_{\mathbf{8}}$ & $\mathbf{O}_{\mathbf{2}}$ & $\mathbf{N}_{\mathbf{2}}$ & $\mathbf{C O}_{\mathbf{2}}$ & \\
\hline 400 & 2.3 & 5.7 & 5.9 & 0.8 & 1.4 & 0.8 & 0.5 & 7.4 & 40.9 & 34.3 & 5.9 \\
500 & 3.7 & 15.1 & 10.9 & 1.5 & 2.6 & 1.0 & 0.7 & 5.5 & 24.7 & 34.3 & 11 \\
600 & 17.1 & 9.4 & 23.1 & 1.4 & 4.2 & 1.2 & 0.7 & 4.3 & 17.3 & 21 & 18.1 \\
\hline
\end{tabular}

\subsection{Energy Yield and Recovery}

Figure 6a shows the energy yield values calculated by Equation (3). Among the products, char had higher energy yields than bio-oil and gas. The energy yield of char was $6.3 \mathrm{MJ} / \mathrm{kg}$ and reduced to almost half $(3.4 \mathrm{MJ} / \mathrm{kg})$ when temperature was increased from 400 to $500^{\circ} \mathrm{C}$. The heating value did not change significantly from 500 to $600{ }^{\circ} \mathrm{C}$. The energy yields of bio-oil and gas increased with increasing 
temperature. The energy yields are consistent with the results of product yields, as energy yields are a function of product yields. The total amount of energy yielded by all products at $400{ }^{\circ} \mathrm{C}$ was almost near wood $(8 \mathrm{MJ} / \mathrm{kg})$. The energy of natural coal is $28 \mathrm{MJ} / \mathrm{kg}$, which is almost four times higher than char. Similarly, natural gas $(56 \mathrm{MJ} / \mathrm{kg}$ ) has almost a hundred times greater energy yield than gas.
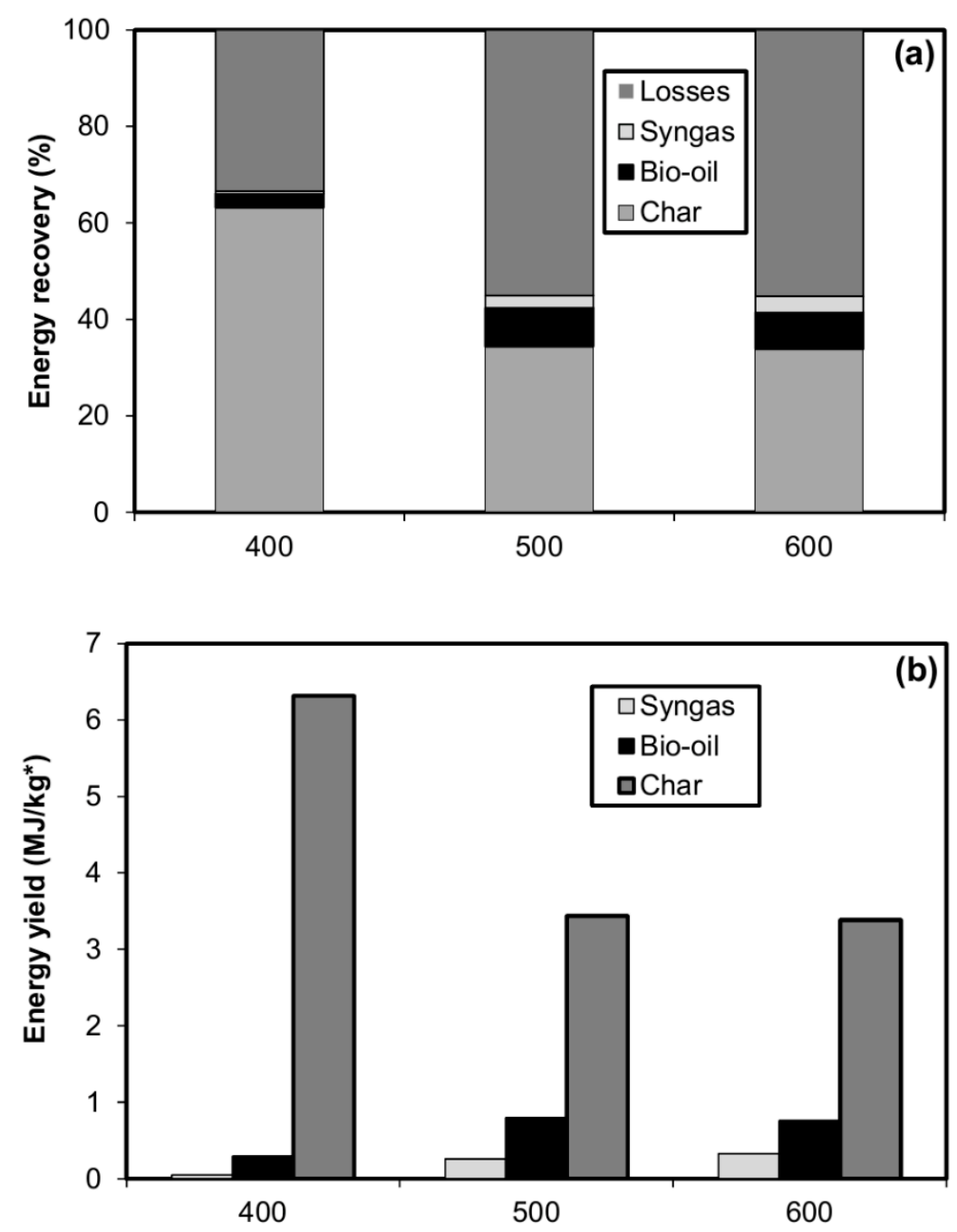

Figure 6. Energy yields (a) and energy conversion efficiency (b) at different temperatures.

Figure $6 \mathrm{~b}$ endorses that the energy losses were less in low temperature which increased with increasing temperature. Haykiri-Acma et al. [28] also reported that the losses are increased at higher temperature. This is due to high rate of heat transfer. The low temperatures showed that the mass transfer rate is also low (from solid to vapors). The Figure $6 \mathrm{~b}$ shows energy recovery (\%) from biomass at the three temperatures. At $400{ }^{\circ} \mathrm{C}$, the energy recovery was approximately $65 \%$. The losses are generally attributed to the production of non-combustible materials like water and $\mathrm{CO}_{2}$.

\section{Conclusions}

Pyrolysis of dried anaerobic sludge produces high valued products that can increase sludge applicability and reduce the risk of disposal. Temperature played an important role in product yields with an improved quality. The quantity of bio-oil was found maximum at $500^{\circ} \mathrm{C}$. The ultimate analysis showed that there was not a significant difference in chemical composition of bio-oil, but the organic composition was changed at different temperatures. The relative abundance of phenols $(29.6 \%)$, alkanes $(9.0 \%)$, alkenes $(12.9 \%)$, and benzene $(8.3 \%)$ in bio-oil were found responsible for the heat and 
energy recovery from sludge. The quantity of char reduced with increasing temperature by decreasing volatile combustible materials and increasing fixed carbon. The energy yield of char was found higher than bio-oil and gas. The high heating value of gas increased with increasing temperature as $\mathrm{C}_{n} \mathrm{H}_{n}$ increased. The study confirmed that the anaerobic sludge is a promising biomass for producing biofuels, and temperature should be optimized to get a desired quantity and/or quality of products.

Author Contributions: Conceptualization, S.C.C., M.U.H. and A.B.; data curation, M.U.H. and H.I.; investigation, M.U.H., M.Z. and M.A.; methodology, S.C.C.; supervision, S.C.C.; validation, B.F.F., M.A. and A.W.; visualization, A.W., A.B. and M.Z.; writing—original draft, M.U.H., M.Z., S.C.C., H.I., M.A., B.F.F., A.B. and A.W.; writing一review and editing, M.U.H., M.Z., S.C.C., H.I., M.A., B.F.F., A.B. and A.W. All authorship must be limited to those who have contributed substantially to the work reported. All authors have read and agreed to the published version of the manuscript.

Funding: This research received no external funding.

Conflicts of Interest: The authors declare no conflict of interest.

\section{References}

1. Laturnus, F.; von Arnold, K.; Gron, C. Organic Contaminants from Sewage Sludge Applied to Agricultural Soils. Environ. Sci. Pollut. Res. 2007, 14, 53-60. [CrossRef]

2. Karaca, C.; Sözen, S.; Orhon, D.; Okutan, H. High temperature pyrolysis of sewage sludge as a sustainable process for energy recovery. Waste Manag. 2019, 78, 217-226. [CrossRef]

3. Sheng, G.P.; Yu, H.Q. Characterization of extracellular polymeric substances of aerobic and anaerobic sludge using three-dimensional excitation and emission matrix fluorescence spectroscopy. Water Res. 2006, 40, 1233-1239. [CrossRef]

4. Han, L.; Sun, H.; Ro, K.S.; Sun, K.; Libra, J.A.; Xing, B. Removal of antimony (iii) and cadmium (ii) from aqueous solution using animal manure-derived hydrochars and pyrochars. Bioresour. Technol. 2017, 234, 77-85. [CrossRef]

5. McKendry, P. Energy production from biomass (part 1): Overview of biomass. Bioresour. Technol. 2002, 83, 37-46. [CrossRef]

6. Kan, T.; Strezov, V.; Evans, T.J. Lignocellulosic biomass pyrolysis: A review of product properties and effects of pyrolysis parameters. Renew. Sustain. Energy Rev. 2016, 57, 1126-1140. [CrossRef]

7. Riley, D.; Forster, C. An evaluation of an autothermal aerobic digestion system. Process Saf. Environ. Prot. 2002, 80, 100-104. [CrossRef]

8. Demirbas, A. Methylation of wood fatty and resin acids for production of biodiesel. Fuel 2011, 90, $2273-2279$. [CrossRef]

9. Wzorek, M. Characterisation of the properties of alternative fuels containing sewage sludge. Fuel Process. Technol. 2012, 104, 80-89. [CrossRef]

10. Jin, Z.; Chang, F.; Meng, F.; Wang, C.; Meng, Y.; Liu, X.; Wu, J.; Zuo, J.; Wang, K. Sustainable pyrolytic sludge-char preparation on improvement of closed-loop sewage sludge treatment: Characterization and combined in-situ application. Chemosphere 2017, 184, 1043-1053. [CrossRef]

11. Zhou, J.; Ma, H.; Gao, M.; Sun, W.; Zhu, C.; Chen, X. Changes of chromium speciation and organic matter during low-temperature pyrolysis of tannery sludge. Environ. Sci. Pollut. Res. 2018, 25, 2495-2505. [CrossRef] [PubMed]

12. Molino, A.; Chianese, S.; Musmarra, D. Biomass gasification technology: The state of the art overview. J. Energy Chem. 2016, 25, 10-25. [CrossRef]

13. Molino, A.; Iovane, P.; Donatelli, A.; Braccio, G.; Chianese, S.; Musmarra, D. Steam gasification of refuse-derived fuel in a rotary kiln pilot plant: Experimental tests. Chem. Eng. Trans. 2013, 32, 337-342.

14. Chianese, S.; Fail, S.; Binder, M.; Rauch, R.; Hofbauer, H.; Molino, A.; Blasi, A.; Musmarra, D. Experimental investigations of hydrogen production from $\mathrm{CO}$ catalytic conversion of tar rich syngas by biomass gasification. Catal. Today 2016, 277, 182-191. [CrossRef]

15. García-Moncada, N.; González-Castaño, M.; Ivanova, S.; Centeno, M.Á.; Romero-Sarria, F.; Odriozola, J.A. New concept for old reaction: Novel WGS catalyst design. Appl. Catal. B Environ. 2018, 238, 1-5. [CrossRef]

16. Raheem, A.; Liu, H.; Ji, G.; Zhao, M. Gasification of lipid-extracted microalgae biomass promoted by waste eggshell as CaO catalyst. Algal Res. 2019, 42, 101601. [CrossRef] 
17. Maguyon, M.C.C.; Capareda, S.C. Evaluating the effects of temperature on pressurized pyrolysis of Nannochloropsis oculata based on products yields and characteristics. Energy Convers. Manag. 2013, 76, 764-773. [CrossRef]

18. Guedes, R.E.; Luna, A.S.; Torres, A.R. Operating parameters for bio-oil production in biomass pyrolysis: A review. J. Anal. Appl. Pyrolysis 2018, 129, 134-149. [CrossRef]

19. Figueiredo, C.; Lopes, H.; Coser, T.; Vale, A.; Busato, J.; Aguiar, N.; Novotny, E.; Canel-las, L. Influence of pyrolysis temperature on chemical and physical properties of biochar from sewage sludge. Arch. Agron. Soil Sci. 2018, 64, 881-889. [CrossRef]

20. Menndez, J.; Inguanzo, M.; Pis, J. Microwave-induced pyrolysis of sewage sludge. Water Res. 2002, 36, 3261-3264. [CrossRef]

21. Parikh, J.; Channiwala, S.; Ghosal, G. A correlation for calculating HHV from proximate analysis of solid fuels. Fuel 2005, 84, 487-494. [CrossRef]

22. Monnet, F. An introduction to anaerobic digestion of organic wastes. In Remade Scotland; Final Report Biogasmax; 2003.

23. Mohan, D.; Pittman, C.U., Jr.; Steele, P.H. Pyrolysis of Wood/Biomass for Bio-oil: A Critical Review. Energy Fuels 2006, 20, 848-889. [CrossRef]

24. Yorgun, S.; Sensoz, S.; Kockar, O.M. Characterization of the pyrolysis oil produced in the slow pyrolysis of sunflower-extracted bagasse. Biomass Bioenergy 2001, 20, 141-148. [CrossRef]

25. Bu, Q.; Lei, H.; Ren, S.; Wang, L.; Zhang, Q.; Tang, J.; Ruan, R. Production of phenols and biofuels by catalytic microwave pyrolysis of lignocellulosic biomass. Bioresour. Technol. 2012, 108, 274-279. [CrossRef] [PubMed]

26. Pan, P.; Hu, C.; Yang, W.; Li, Y.; Dong, L.; Zhu, L.; Tong, D.; Qing, R.; Fan, Y. The direct pyrolysis and catalytic pyrolysis of Nannochloropsis sp. residue for renewable bio-oils. Bioresour. Technol. 2010, 101, 4593-4599. [CrossRef]

27. Valliyappan, T.; Ferdous, D.; Bakhshi, N.N.; Dalai, A.K. Production of hydrogen and syngas via steam gasification of glycerol in a fixed-bed reactor. Top. Catal. 2008, 49, 59-67. [CrossRef]

28. Haykiri-Acma, H.; Yaman, S.; Kucukbayrak, S. Effect of heating rate on the pyrolysis yields of rapeseed. Renew. Energy 2006, 31, 803-810. [CrossRef]

(C) 2019 by the authors. Licensee MDPI, Basel, Switzerland. This article is an open access article distributed under the terms and conditions of the Creative Commons Attribution (CC BY) license (http://creativecommons.org/licenses/by/4.0/). 